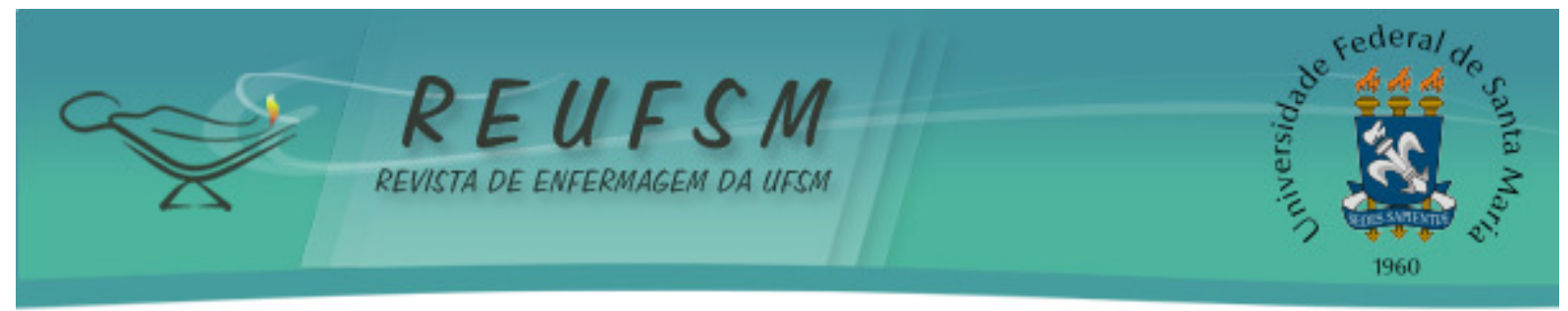

ARTIGO ORIGINAL

\title{
ATENÇÃO EM SAÚDE NO PLANEJAMENTO REPRODUTIVO: ATITUDES E PRÁTICAS DE ENFERMEIROS
}

\section{HEALTH CARE IN REPRODUCTIVE PLANNING: ATTITUDES AND NURSES' PRACTICES ATENCIÓN DE SALUD EN LA PLANIFICACIÓN REPRODUCTIVA: ACTITUDES Y PRÁCTICAS} ENFERMERAS

Doi: $10.5902 / 2179769220490$

\author{
Maryla Pinto Almeida ${ }^{1}$ \\ Mônica Cecília Pimentel de Melo \\ Lucineide Santos Silva ${ }^{3}$ \\ Ana Dulce Batista dos Santos ${ }^{4}$
}

RESUMO: Objetivo: analisar a atenção em saúde, empregada por enfermeiros, no planejamento reprodutivo, por meio de equipes de saúde da família de Juazeiro, Bahia. Método: qualitativo, exploratório e descritivo, por meio de entrevista semiestruturada, com oito enfermeiros de cinco Unidades Saúde da Família, com maior número de mulheres em idade fértil. Resultados: emergiram escassez e irregularidade no fornecimento dos métodos, comprometendo a eficácia e a qualidade do planejamento reprodutivo. A inconstância das atividades educativas apontou para mulheres e/ou casais desinformados sobre uso e benefícios desses métodos, revelando a automedicação e busca nas farmácias comerciais. Conclusões: a construção de uma atenção em saúde que atue nas premissas da qualidade, efetividade e equidade poderá contribuir para uma enfermagem mais autônoma e condizente com as necessidades da população no planejamento reprodutivo.

Descritores: Planejamento familiar; Atenção primária a saúde; Saúde da família; Enfermagem em saúde pública.

ABSTRACT: Aim: to analyze the attention on health care employed by nurses at the reproductive planning, by family health teams from Juazeiro, Bahia. Method: qualitative, exploratory and descriptive study in which was used semi-structured interview with eight nurses from five Family Health Units, with the largest number of women at childbearing age. Results: scarcity and irregularity in the supply of the methods emerged, compromising the effectiveness and quality of reproductive planning. The instability of the educational activities pointed at women and/or couples uninformed about the use and benefits of these methods, revealing self-medication and search in pharmacies. Conclusions: the construction of an attention on health care that acts in the premises of the quality, effectiveness and equity can contribute to a more autonomous nursing that is also consistent with the needs of the population in reproductive planning.

Descriptors: Family planning; Primary care health; Family health; Nursing in public health.

\footnotetext{
${ }^{1}$ Enfermeira. Residente em Saúde da Família pela Universidade Federal do Vale do São Francisco (UNIVASF). Petrolina-PE. Brasil. lylapalmeida@hotmail.com

2 Enfermeira. Docente em Enfermagem da Universidade Federal do Vale do São Francisco (UNIVASF). Doutoranda em Educação pelo PPG Educação em Ciências, Química da Vida e Saúde com Associação de IES UFRGS/UFSM/FURG. Petrolina-PE. Brasil. monquinamelo@gmail.com

${ }^{3}$ Enfermeira. Docente em Enfermagem da Universidade Federal do Vale do São Francisco (UNIVASF). Mestre em Enfermagem pela Universidade Federal da Bahia (UFBA). Petrolina-PE. Brasil. enflucineide@hotmail.com

${ }^{4}$ Enfermeira. Docente em Enfermagem da Universidade Federal do Vale do São Francisco (UNIVASF). Mestre em Enfermagem pela Universidade Federal do Rio Grande do Norte (UFRN). Petrolina-PE. Brasil. anadulcebs@yahoo.com.br
} 


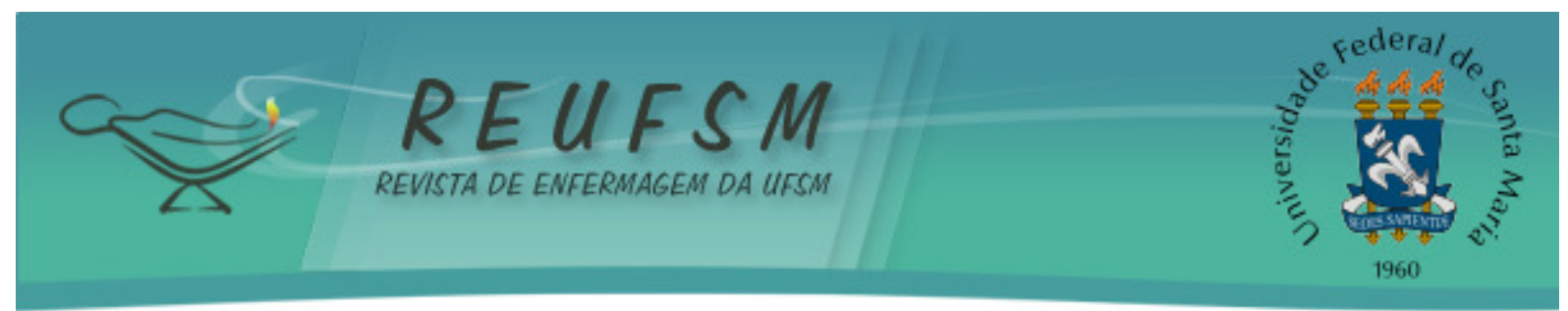

RESUMEN: Objetivo: analizar la atención de salud, empleada por enfermeros, en la planificación reproductiva, por los equipos de Salud Familiar de Juazeiro, Bahía. Método: cualitativo, exploratorio y descriptivo, realizado a través de entrevista semiestructurada, con ocho enfermeras de cinco Unidades de salud de la Familia, con el mayor número de mujeres en edad fértil. Resultados: surgieron la escasez y la irregularidad en el suministro de los métodos, que comprometieron la efectividad y calidad de la planificación reproductiva. La inconstancia de actividades educativas dirigidas para mujeres y/o parejas desinformadas sobre el uso y beneficios de estos métodos, revelando la automedicación y busca en las farmacias comerciales. Conclusiones: la construcción de una atención de salud que actúe en las premisas de calidad, eficacia y equidad puede contribuir para una enfermería más autónoma y coherente con las necesidades de la población en la planificación reproductiva.

Descriptores: Planificación familiar; Atención primaria de salud; Salud de la familia; Enfermeras de salud pública.

\section{INTRODUÇÃO}

O direito à cidadania, à assistência clínico-ginecológica integral, o acesso à contracepção, o conhecimento dos métodos por meio de práticas educativas e, em decorrência desse último, a oportunidade da escolha livre e informada, foram conquistas adquiridas por meio do Programa de Assistência Integral à Saúde da Mulher (PAISM), criado em 1983/84. Esses alcances do programa foram mantidos e ampliados na Política Nacional de Atenção à Saúde da Mulher (PNAISM) que incorporou a Lei do Planejamento Familiar, $n^{\circ} 9.263 / 96$. $^{1-4}$

No ano de 2009, essa terminologia "planejamento familiar" foi modificada para "planejamento reprodutivo (PR)", englobando mulheres nas diversas opções sexuais, desde relação conjugal estável, vida sexual sem parceiros estáveis e as que planejam iniciar sua vida sexual. ${ }^{2}$ Contudo, nos serviços de saúde o termo "planejamento familiar" (PF) prevalece sendo o mais difundido, o que denota a hegemonia de paradigmas que associam a vida sexual ao contexto de formação de uma família. ${ }^{5}$

A assistência ao PR, atualmente, é realizada pelas Unidades de Saúde da Família (USF), nas quais se enfrentam algumas deficiências nas suas etapas de implementação, particularmente na assistência contraceptiva reversível e nos procedimentos contraceptivos cirúrgicos, ocasionadas pela baixa capacidade de atender a demanda. ${ }^{1,6}$ Outro entrave na assistência é o fornecimento insatisfatório/irregular dos métodos, devido à incorreta ou restrita provisão realizada na unidade de saúde, acarretando menos opções de métodos para os usuários no momento da escolha. ${ }^{6-7}$

Nessa conjuntura, os enfrentamentos do PR ainda dizem respeito às poucas ações voltadas para saúde reprodutiva masculina e às questões de infertilidade. ${ }^{4,7} \mathrm{~A}$ participação dos homens nas ações do PR precisam extrapolar as questões relacionadas à opção pela vasectomia e/ou uso de preservativos. É imperiosa uma abordagem que contemple aspectos de masculinidade, virilidade, paternidade e cidadania, de modo que eles percebam sua importância para além do apoio financeiro às companheiras na aquisição de contraceptivos. ${ }^{8}$

Em relação à infertilidade, estudo realizado com enfermeiros que atuam na atenção primária de Fortaleza-CE constatou que a maioria desses profissionais desconhece suas atribuições, inclusive no que tange à orientação do período fértil e condutas adequadas para propiciar a concepção. ${ }^{9}$ Entretanto, os déficits de formação acerca do PR, entre esses profissionais, muitas vezes, são abrangentes. Alguns deles não estão capacitados para solucionar dúvidas e problemas cotidianos do PR, sendo importante salientar que a capacitação desses profissionais deve ser uma ação centrada no processo e no campo de trabalho e realizada de forma contínua e multidisciplinar. ${ }^{4,9}$ 


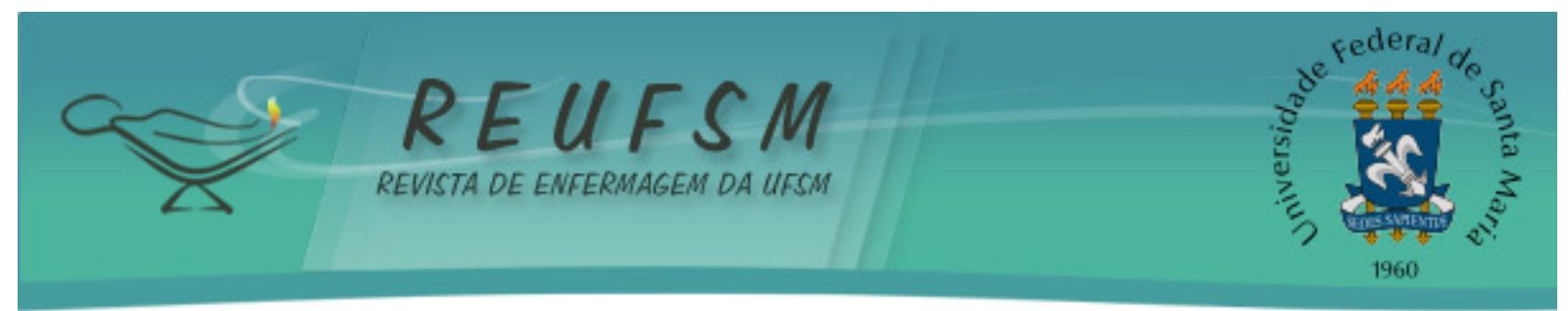

Portanto, é possível observar que a assistência ao PR continua associada a um cuidado centrado nas questões contraceptivas, influenciada por crenças e valores sociais que vinculam o planejamento familiar ao controle da prole. ${ }^{4,6-7}$ Além disso, prevalecem concepções de gênero hegemônicas que designam às mulheres a responsabilidade pela limitação do tamanho da família; a baixa articulação com a prevenção de infecções sexualmente transmissíveis e o consequente incentivo ao uso do preservativo; a dispensação de métodos sem acompanhamento clínico regular e o pouco investimento para assistir mulheres ou casais com queixas de infertilidade. ${ }^{5,9}$

Ademais, considerando a criação da legislação e a implementação de políticas públicas voltadas ao PR para auxiliar os profissionais atuantes nas USF, em específico os enfermeiros, e a divergência entre a proposta da estratégia ministerial e a prática das unidades, evidenciada por observações empíricas da prática cotidiana, destaca-se como objeto de estudo, a atenção em saúde empregada por enfermeiros no PR. 0 estudo busca responder a seguinte questão de pesquisa: como se dá a atenção em saúde, empregada por enfermeiros, no planejamento reprodutivo, no município de Juazeiro-BA? Dessa forma, o estudo tem como objetivo analisar a atenção em saúde, empregada por enfermeiros, no $\mathrm{PR}$, por meio de equipes de saúde da família de Juazeiro, Bahia.

Nos discursos desses sujeitos certamente há, muito além de relatos da sua práxis, a expressividade de seus enfrentamentos, estratégias e vivências, na perspectiva de pontuar as principais fragilidades que persistem e dificultam a qualidade da assistência prestada por esses profissionais.

\section{MÉTODO}

Qualitativo, exploratório e descritivo, desenvolvido em Juazeiro, Bahia. ${ }^{10-11} \mathrm{~A}$ atenção primária à saúde desse município é composta por 44 USF, com um total de 54 equipes, que dispõe de médicos, enfermeiros, odontólogos, agentes comunitários de saúde, técnicos de enfermagem e técnicos de saúde bucal. 0 município tem 27 USF localizadas na zona urbana, destas, cinco foram utilizadas como lócus de pesquisa.

A eleição das cinco unidades, em ordem de maior quantitativo de mulheres em idade fértil, compreendido entre 10 e $49 \operatorname{anos}^{9}$, no ano de 2013, foi suficiente para se atingir o fenômeno da saturação. ${ }^{11-12}$ Participaram do estudo oito enfermeiros, que constituíram uma amostra, do tipo intencional e o fechamento amostral se deu por saturação teórica.

O critério de inclusão foi a opção por enfermeiros que atuavam nas USF localizadas na zona urbana, atuantes e não afastados do serviço no período de outubro a novembro de 2014, correspondente à coleta do material empírico. Optou-se em excluir os enfermeiros atuantes em zona rural, devido às dificuldades de locomoção nessas áreas.

Foi empregada a entrevista semiestruturada, por meio de gravação de áudio, realizada no interior do consultório da USF, em que o enfermeiro atuava. 0 material empírico foi transcrito e analisado pela técnica da Análise de Discurso. ${ }^{13}$ Vale ressaltar que foram realizadas correções de linguagem para melhor compreensão dos discursos, todavia, o sentido e a essência dos mesmos não foram alterados. Por conseguinte, as respostas foram analisadas e agrupadas em categorias para auxiliar e dinamizar a interpretação das informações relatadas pelos entrevistados.

A pesquisa foi aprovada pelo Comitê de Ética da Universidade Federal do Vale do São Francisco (CEDEP/UNIVASF), sob $n^{\circ}$ 0008/180814, em 18 de agosto de 2014. Foram respeitados todos os aspectos éticos contidos na resolução 466/2012 do Conselho Nacional de Saúde, inclusive no que tange à confidencialidade, sigilo e privacidade. Todos os enfermeiros que aceitaram participar da pesquisa assinaram o Termo de Consentimento 


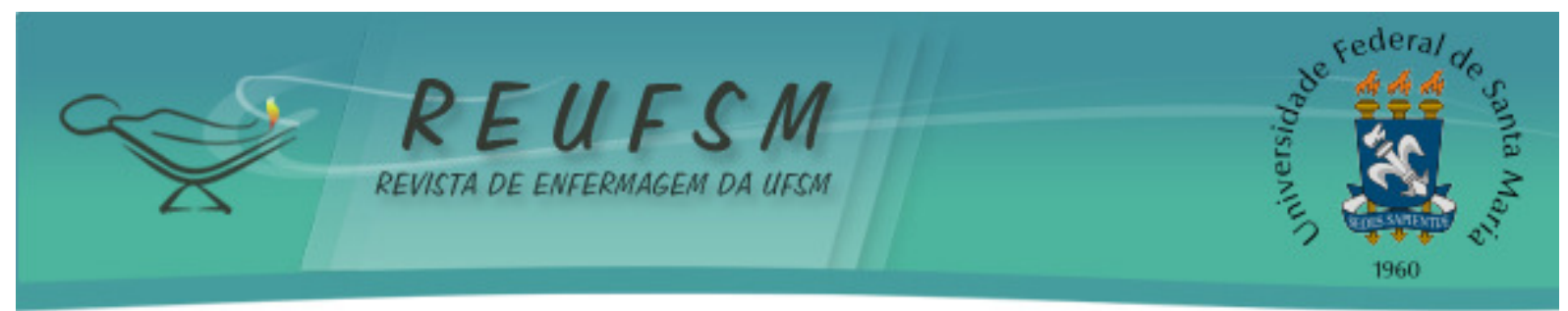

Livre e Esclarecido (TCLE) em duas vias. Ademais, foi assegurada a manutenção do sigilo e da confidencialidade, identificando os discursos apenas pela inicial "E" (entrevista) e enumerando-os de acordo com a ordem da aplicação da entrevista.

\section{RESULTADOS E DISCUSSÃO}

A partir da análise das entrevistas foi possível formular quatro categorias que discorrem sobre a escassez de métodos contraceptivos nas USF, os entraves na gestão do PR, a assistência com ênfase no modelo biomédico e a consequente lacuna nas ações educativas. Essas categorias foram intituladas: "Tecnologias contraceptivas: tenho escolha?", "Além da falta dos insumos, outros enfrentamentos", "A face do planejamento reprodutivo: ações centralizadas no modelo biomédico" e "Distanciamento entre o planejamento reprodutivo e o ideário de educação em saúde".

\section{Tecnologias contraceptivas: tenho escolha?}

Um dos objetivos do PR é a assistência à saúde reprodutiva do casal, com a escolha livre e informada na demanda por concepção ou contracepção, o que exige do serviço a disponibilidade diversificada de insumos e tecnologias conceptivas e contraceptivas. ${ }^{1,14}$ Contudo, é notório que a escassez ou falta desses recursos comprometem a eficácia e a qualidade do programa. O programa do PR está disponível em muitas unidades, entretanto, sua efetividade é comprometida pela baixa adesão dos usuários ocasionada, principalmente, pela irregularidade no fornecimento dos métodos contraceptivos nos serviços de saúde. ${ }^{3,7}$ Corroborando com a assertiva, seguem os discursos.

[...] agora, como a gente não disponibiliza mais o método, dificultou mais das pacientes virem até a gente [...]. Só estou tendo preservativo masculino. [...] Porque não adianta a gente orientar que existe o método tal, e quando ela falar "gostei do DIU [Dispositivo Intra Uterino]", aí, ela tem que comprar para ser colocado pela ginecologista [...]. (E5)

[...] elas não tem tanto interesse em vir para a unidade sem ter a medicação [...]. O controle de natalidade tem que ser feito para algumas situações. [...]. (E1)

Nota-se, no último depoimento, a ideia de controle de prole relacionada ao suprimento de métodos contraceptivos, retomando as abordagens primárias com que o programa de PR foi concebido e compreendido pelas políticas vigentes da época. ${ }^{7}$ A lei $n^{\circ}$ 9.263/1996 traz a regulação do planejamento familiar e enfatiza a proibição das ações de saúde direcionadas ao controle populacional. ${ }^{6,9,15}$

Os discursos referentes ao controle demográfico, por muitos anos, geraram indignação na população, principalmente nos movimentos feministas, que reivindicam os direitos das mulheres quanto à decisão de procriar, a ruptura do papel social de mulher submissa e a vivência plena da sexualidade. ${ }^{2}$ Os direitos sexuais e reprodutivos precisam ser entendidos e anexados a todos os demais direitos humanos, pois a capacidade de reprodução, a decisão de quando e a frequência com que isso ocorrerá, é direito de cada cidadão. Todavia, para o pleno exercício desses direitos se fazem necessárias políticas públicas que assumam e implementem verdadeiramente a responsabilização com a promoção à saúde, com atitudes profissionais livres de discriminação e preconceito. ${ }^{3,16-17}$ 


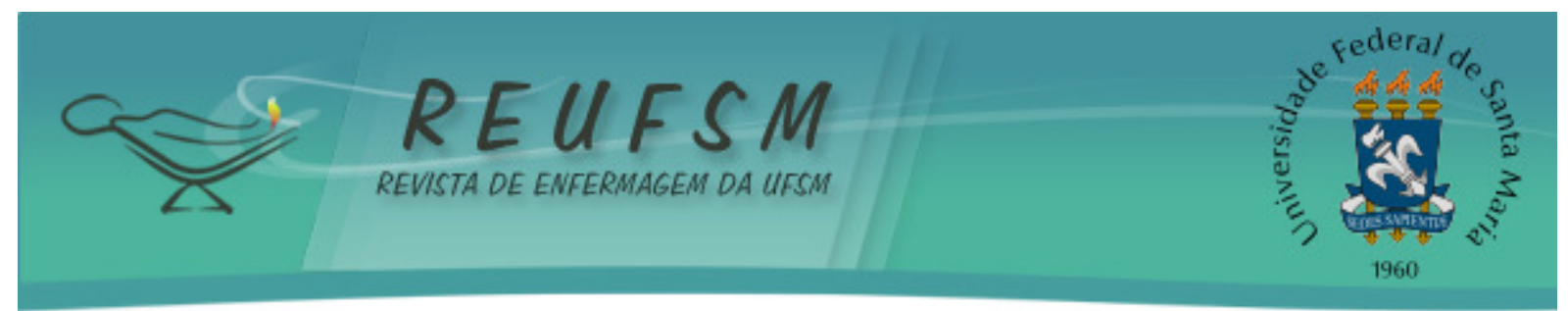

Outro aspecto observado foi a reduzida procura e utilização do preservativo feminino pelas usuárias do serviço. Sabe-se que, além de propiciar maior autonomia para que as mulheres tenham sexo com proteção, pode ampliar a sensação de prazer das usuárias, tendo em vista o contato do anel externo com o clitóris. Ademais, dispensa a necessidade de ereção peniana para sua colocação, e é bem lubrificado, podendo ser introduzida horas antes da relação sexual. ${ }^{18}$ Apesar de todos esses benefícios, os depoentes enfatizaram:

sai muito pouco também [preservativo feminino]. Só tenho duas pacientes que utilizam, e aí, só posso entregar cinco, porque é pouquinho [...]. (E3)

só tenho preservativo masculino e feminino. [...] Elas dão preferência ao masculino mesmo. (E4)

A desinformação e o desconhecimento sobre o uso e os benefícios do preservativo feminino são os principais motivos pela baixa procura, além disso, o alto custo limita a quantidade disponível nos serviços de saúde. ${ }^{18}$ Por esse motivo, é fundamental, para ampliar a sua procura, a capacitação e sensibilização dos profissionais, a fim de difundir e orientar quanto ao uso da camisinha feminina, seguida da maior oferta desta nos serviços de saúde. ${ }^{18}$

Aspectos culturais também influenciam na sua pouca utilização, pois a dominação masculina na relação sexual acaba dificultando o processo de negociação, ocasionando a perda da autonomia feminina.,18

No que diz respeito à contracepção de emergência, o discurso dos enfermeiros corroborou com o resultado de um estudo desenvolvido no Recife-PE, no qual assumem que um dos principais motivos para não indicarem decorre do receio de que o seu uso se torne rotina". ${ }^{19}$ Dessa forma, negam o amplo acesso aos direitos sexuais e reprodutivos dos usuários, como evidenciado abaixo:

não, não sai muito [pílula do dia seguinte], porque a gente não divulga. [...] quando vem no dia do planejamento familiar, aí, vem se queixando que tomou [...]. (E3)

A lacuna deixada pela não distribuição do método, mediada por valores profissionais que ferem os princípios norteadores dos direitos sexuais e reprodutivos, associada à falta de orientação para a clientela, tem levado muitas mulheres a adquirirem o contraceptivo nas farmácias comerciais, expondo-as aos riscos da automedicação.

A manifestação dessa situação se torna clara quando a quase totalidade dos entrevistados expuseram que as mulheres já compraram o método sem receita médica. A aquisição de outros métodos anticoncepcionais em farmácias comerciais se tornou comum nas unidades pesquisadas e tem se revelado como fator primordial para a pouca procura pelo programa, dificultando o processo de orientação e acompanhamento da clientela.

Logo, o acesso comprometido às tecnologias contraceptivas no programa de planejamento reprodutivo, aliado à inadequada e/ou ausente orientação dos métodos disponíveis, desafia os preceitos da integralidade e da equidade nos serviços públicos de saúde. ${ }^{7}$

Além da falta dos insumos, outros enfrentamentos

O discurso destaca a incipiência na abordagem em saúde sexual e reprodutiva masculina, pois a participação dos homens no programa é quase inexistente no serviço pesquisado. 


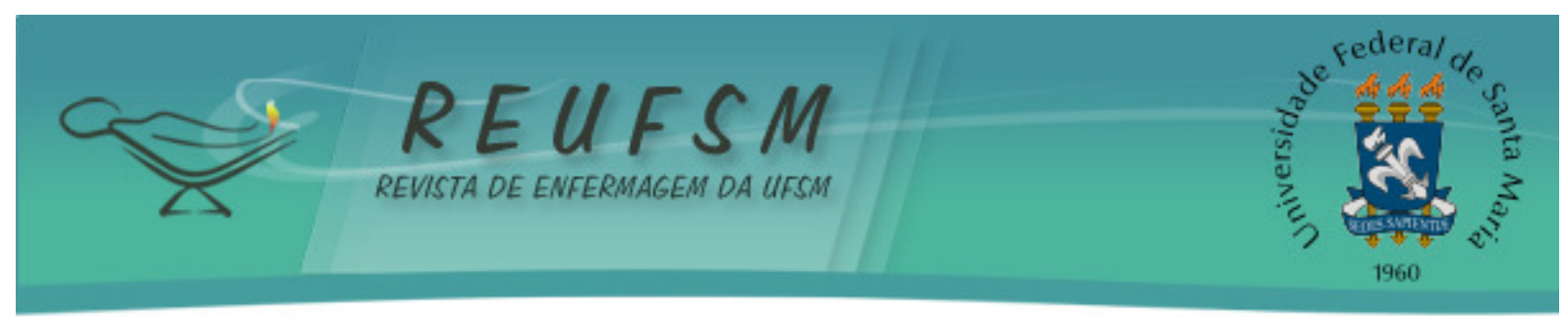

[...] o homem deixa para a mulher, e eu, profissional, também estava deixando para a mulher [...]. (E6)

O PR, por muito tempo, foi direcionado às mulheres e, até os dias atuais, os reflexos dessa atitude são sentidos nos serviços de saúde, tornando-as as únicas responsáveis pela procura dos métodos contraceptivos, permitindo, então, a omissão da responsabilidade masculina no processo contraceptivo. ${ }^{19-20}$ Corroborando com essa assertiva, percebe-se, por meio do discurso, a necessidade de capacitações em serviço, pois a formação acadêmica pouco se aprofunda nas discussões referentes aos direitos reprodutivos de homens e adolescentes, tampouco na importância de trabalhos educativos com essa temática. ${ }^{14,17,21}$

[...] a política, a gente não sabe não [...] a gente não sabe essa parte do adolescente ter direitos reprodutivos [...] eu nunca ouvi na faculdade "direito reprodutivo" [...]. (E6)

Nessa perspectiva de cuidado, de promoção à saúde sexual e reprodutiva, sob a égide dos direitos humanos, pautados na integralidade e nas questões de gênero, torna-se um desafio para o enfermeiro concretizar os direitos sexuais e reprodutivos, em que se incluem o casal, os homens, as mulheres que se definem homossexuais e/ou bissexuais e os adolescentes.

A pesquisa realizada com adolescentes do Rio de Janeiro demonstrou que os serviços e os profissionais de saúde não são as principais fontes de informação e orientação sobre saúde sexual e reprodutiva. Entre as causas, estão a pouca confiança e inadequado acolhimento. Dessa forma, as capacitações focadas na assistência aos adolescentes buscam a ampliação do vínculo e, com isso, o fortalecimento das práticas de cuidado. ${ }^{22}$

A dificuldade na assistência aos adolescentes, no programa de $P R$, foi 0 enfrentamento que também surgiu nos discursos.

[...] é muito difícil a gente pegar uma adolescente para iniciar o planejamento familiar [...]. (E1)

[...] eu tenho um problema sério: a questão do adolescente [...]. Uma média de mais ou menos cinco gestantes menores de 20 anos [...]. (E4)

Essa dificuldade ocorre porque os adolescentes se encontram ausentes das USF, pois a organização dessas unidades ainda é muito voltada para o perfil materno-infantil, não acolhendo o indivíduo de forma integral. As políticas específicas para os adolescentes se apresentam incipientes, exigindo dos profissionais de saúde a criação de alternativas e ações que priorizem essa fase da vida. ${ }^{21,23} \mathrm{Com}$ o início sexual cada vez mais precoce é fundamental que os jovens sejam orientados sobre seus direitos e, especialmente, sobre cuidados preventivos, visto que suas práticas sexuais e reprodutivas irão repercutir na sua saúde, educação e vida. ${ }^{23}$

A assistência de enfermagem ao programa de planejamento reprodutivo enfrenta outros entraves revelados nos discursos abaixo:

não poder prescrever medicação [...]. (E3)

a gente não poder iniciar, porque aí não tem a procura e elas não querem só orientação [...]. Aí, elas só querem o médico [...]. (E8) 


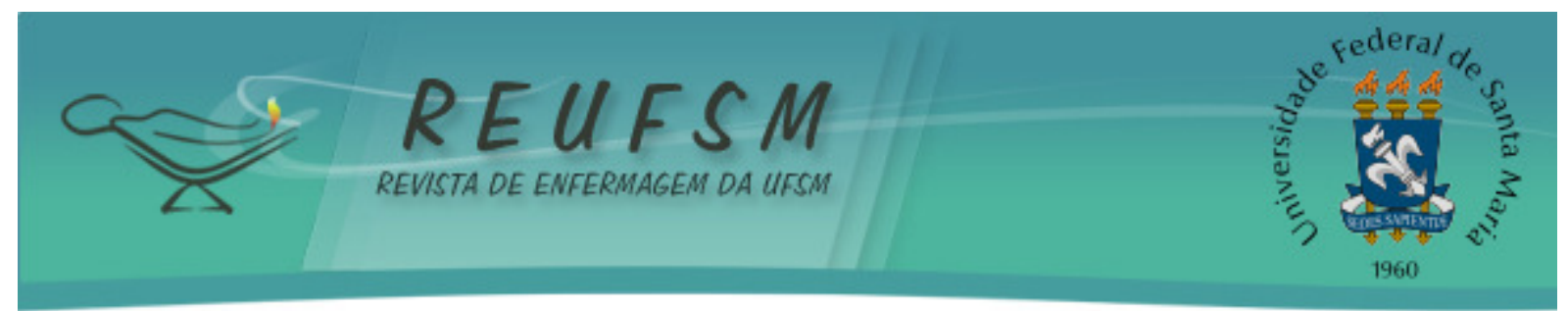

Nos lócus pesquisados todos os enfermeiros estudados atuavam somente na transcrição de receitas médicas, durante as consultas de acompanhamento, o que difere do estudo realizado no Ceará, cujos profissionais atuavam em todas as etapas do atendimento do PR. ${ }^{6}$

Eu acho que a dificuldade da comunidade é em entender que o enfermeiro não pode estar prescrevendo método. Acho que a questão, também, da gente não ter um protocolo de enfermagem atualizado e mais detalhado [...]. (E2)

A não prescrição dos métodos anticoncepcionais é uma barreira das instituições de saúde e dos próprios profissionais, visto que se encontram respaldados pela Lei do Exercício Profissional do Enfermeiro $n^{\circ} 7.498 / 1986$, Decreto $n^{\circ} 94.406 / 87$ e a Portaria $1.625 / 2007$, que estabelecem a prescrição pelo enfermeiro, como membro da equipe de saúde, dos medicamentos vinculados aos programas de Saúde Pública, acordados com a gestão municipal e estadual. ${ }^{24}$ Acredita-se que o receio no ato de prescrever ocorra devido às constantes mudanças na legislação, não sabendo de fato os direitos atribuídos à sua profissão e, também, pela insegurança na formação, ainda muito direcionada à preparação e administração dos medicamentos. ${ }^{24}$

0 enfermeiro, enquanto parte integrante das etapas fundamentais para a efetividade do PR, realiza a dispensação dos métodos contraceptivos; tem papel indispensável no processo educativo aos usuários; identifica problemas e intervém em ações e atitudes que podem comprometer a eficácia do método de escolha, buscando conhecer os múltiplos determinantes, sociais, culturais e econômicos envolvidos nas ações de saúde. ${ }^{4}$

Portanto, a ausência e/ou o desconhecimento de normas e protocolos institucionais interferem no atendimento integral do PR e na autonomia dos enfermeiros. Advoga-se, desse modo, a necessidade de divulgação das rotinas e protocolos, criados e reconhecidos pelos gestores municipais, em conformidade com as legislações vigentes, para assegurar a atuação de qualidade e segura em programas da atenção primária, especificamente no PR. ${ }^{6}$

O programa de PR é complexo e necessita de políticas públicas eficazes e fortalecidas, bem como da concreta atuação dos gestores de saúde, como exemplificado no depoimento abaixo:

[...] sem ter um apoio, um suporte da gestão, acho que não sai disso. (E1)

O envolvimento sensível do gestor, aliado à resolutividade e à efetividade da política local de gestão, promovendo o abastecimento das unidades com insumos básicos, capacitação de recursos humanos e organização da rede de assistência, comprova que o programa pode avançar de forma substancial, fortalecendo o compromisso e a corresponsabilização com a promoção à saúde. ${ }^{7}$

Contudo, é preciso que haja um movimento político organizado, por parte dos enfermeiros, como forma de assegurar o exercício de suas conquistas profissionais, a integralidade da atenção a homens e mulheres, com o respeito aos seus direitos sexuais e reprodutivos, e o fortalecimento do Sistema Único de Saúde (SUS).

\section{A face do planejamento reprodutivo: ações centralizadas no modelo biomédico}

Nas unidades pesquisadas, o PR é desenvolvido, em sua maioria, por consultas de demanda espontânea, conforme ilustram as falas. 


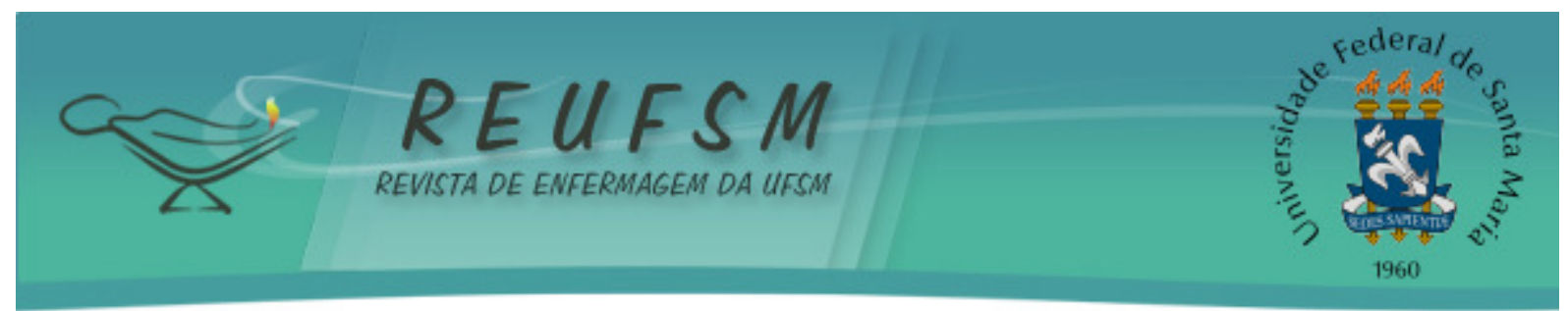

Planejamento aqui está ficando mais a questão de consulta mesmo [...]. Não tem o dia de planejamento [...]. Ele [médico] prescreve e ela [paciente] vai pegar na farmácia popular. [...]. (E3)

[...] o paciente vinha com a prescrição médica, a gente fazia a orientação de como fazer o uso e os cuidados gerais, e aí, dispensava o medicamento, porque ficava com a gente na sala [...]. [...] agora, já marcam para o médico, aí, o médico orienta e passa a prescrição, e elas compram fora. Elas não voltam [para o enfermeiro]. (E7)

A atenção em saúde empregada no PR tem direcionado suas ações na prescrição e na dispensação de métodos por demanda espontânea, fomentando, dessa forma, lacunas no seguimento dos usuários e, como consequência, a descontinuidade de uso ou o emprego equivocado do método. Neste sentido, o cumprimento de ações prioritárias e de equidade estabelecidas pelo SUS, no Brasil, deve vislumbrar atividades educativas antes da obtenção do método na unidade, além da implantação de estratégias que estimulem a participação de homens e mulheres nessas reuniões; consulta médica para a prescrição do método contraceptivo e aquisição, pela unidade, de insumos contraceptivos compatíveis com a demanda de seguimento e com o cadastro de novos usuários para, assim, permitir o direito de cidadania e promoção à saúde. ${ }^{4-5,7}$

Alguns depoimentos apontaram para uma realidade específica de atrelamento dos atendimentos do PR a outros programas ministeriais, desenvolvidos nas unidades de saúde.

A gente aproveitava para fazer no dia que elas vinham para a gente, mas agora até isso está difícil, porque elas não vêm mais. Aí, a gente direciona mais quando a mulher vem fazer o preventivo. [...] e as puérperas também [...]. (E5)

A integração do PR aos atendimentos de preventivo e puerpério se deve ao número satisfatório de pessoas abrangidas por esses programas. Todavia, essa interligação acaba direcionada, exclusivamente, para o público feminino adulto, do paradigma heteronormativo, ou para aquelas que já iniciaram a vida reprodutiva, excluindo adolescentes, mulheres, homens, ou casais que planejam uma gestação e buscam cuidados pré-conceptivos. $^{2}$

\section{Distanciamento entre o planejamento reprodutivo e o ideário de educação em saúde}

É direito de qualquer indivíduo decidir de forma livre e consciente sobre concepção ou contracepção. Contudo, isso depende das informações ofertadas, bem como da qualidade da assistência disponível nos serviços de atenção à saúde. ${ }^{14} \mathrm{~A}$ atividade educativa é o primeiro meio de captação e vinculação de usuários ao programa de PR, porém os discursos evidenciam uma baixa prioridade dessa ação no serviço.

Grupo fixo a gente não tem, mas a gente sempre aborda esse tema no decorrer do ano. Sala de espera? Fazemos, mas não é constante e não é esse tema sobre métodos. (E4)

Nas ações de promoção da saúde, as práticas educativas assumem papel primordial para o protagonismo dos usuários no seu auto cuidado, pois, a partir do 


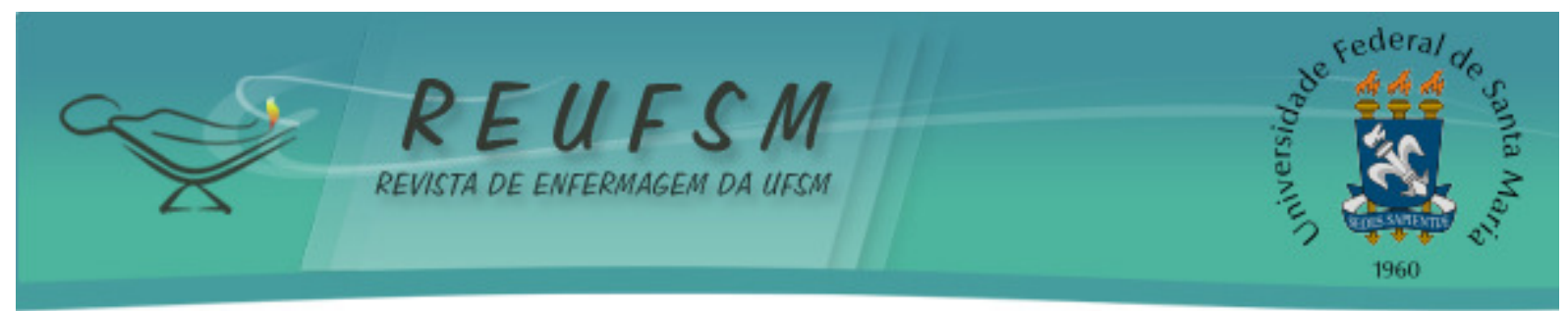

conhecimento, os indivíduos se encontram capacitados para decidir por comportamentos e atitudes mais saudáveis. ${ }^{25}$ Entretanto, necessita-se de compromisso e entendimento da relevância da educação em saúde por parte dos profissionais atuantes na atenção primária, pois, muitas vezes, não a incorporam na rotina dos serviços.

Nos discursos, emerge como principal dificuldade, para o desenvolvimento de grupos educativos, a inadequada infraestrutura das unidades de saúde.

[...] De dois meses para cá, a gente não fez mais nada, porque não tem cadeira, não tem espaço, e porque, antes, a gente até fazia sala de espera [...]. Hoje, nem tenho disponível método e nem tenho espaço para fazer [...]. (E3)

Só sala de espera, já com esse tema e DST, tudo junto, e só temos grupo de gestante, porque não tem espaço [...] e é só o momento que a gente tem, à tarde, porque pela manhã é muito cheio. (E8)

A infraestrutura de uma unidade de saúde é importante para a qualidade da atenção à saúde. No entanto, mesmo diante das adversidades, não se trata de fator fundamental para os bons resultados, pois condições estruturais favoráveis podem ser indevidamente utilizadas, assim como, o trabalho de bons profissionais pode impactar e trazer melhores resultados de intervenção. ${ }^{3}$

0 ambiente escolar, elemento ímpar para utilização em ações do PR, foi mencionado nos discursos devido à sua importância e relevância enquanto dispositivo de acesso para a abordagem com adolescentes, principalmente em relação a temas como sexualidade. Não obstante, apesar desse reconhecimento, constatou-se que a realização de educação em saúde não é uma constante.

Só fica consulta e queixa. [...] a parte educativa deveria ser mais voltada [...] também em escolas [...]. (E3)

[...] palestras, há nas escolas, quando vai na escola. Aqui, palestra não é rotineira. São poucas [...]. (E6)

A escola é um ambiente privilegiado para o desenvolvimento de produção em saúde, por meio de ações voltadas para a prevenção e sua promoção. Apesar disso, para que ocorra essa intersetorialidade é fundamental que as equipes das USF se integrem e se articulem com - ambiente escolar, a fim de discutir ações prioritárias voltadas à realidade dos adolescentes. ${ }^{16,21} \mathrm{~A}$ atuação da atenção primária pode surtir efeitos positivos no lócus escolar, desde que promova uma abordagem aberta e comprometida com as necessidades juvenis.

A atenção em saúde, no PR do estudo, revela limitações e urge por mudanças, pois vem repercutindo em problemas expressivos para os usuários do serviço. Considerando essa expressividade, a inserção e continuidade das atividades educativas no serviço e a eficiência no seu processo, corrobora para a efetividade do PR nos moldes e princípios da integralidade e equidade do SUS.

\section{CONSIDERAÇÕES FINAIS}

Este estudo procurou analisar a atenção em saúde, empregada por enfermeiros, no planejamento reprodutivo, por meio de equipes de saúde da família de Juazeiro, Bahia. Com isso, as dificuldades citadas perpassam por problemas de dimensão organizacional dos 


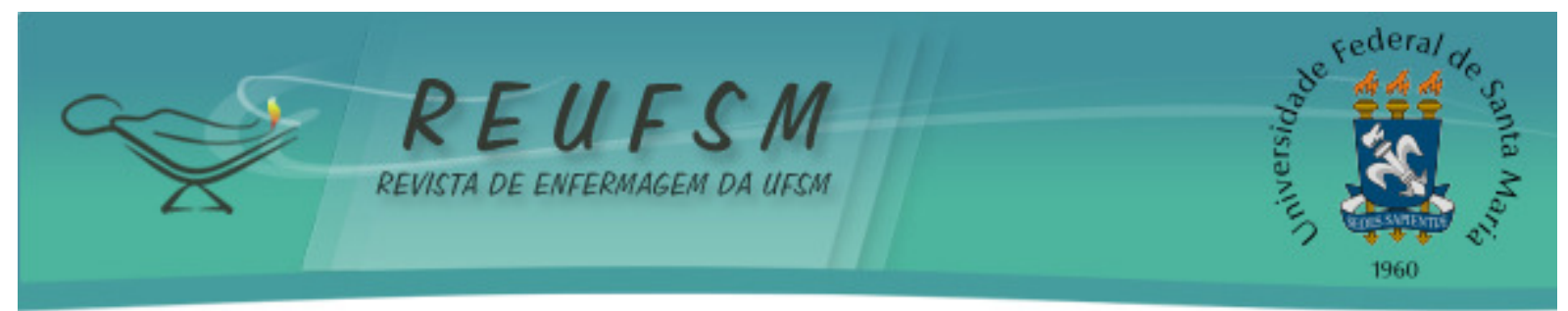

serviços de saúde e assistencial dos profissionais atuantes. Entre eles, a irregularidade no fornecimento dos métodos, resultando na escassez e falta destes nas unidades de saúde, o que compromete a eficácia e a qualidade das etapas do programa.

Como limitação, destacou-se a impossibilidade de aplicação do estudo a todas as USF de Juazeiro-BA, o que poderia resultar em uma pesquisa mais representativa dos reais enfrentamentos no PR pelos enfermeiros.

A enfermagem, enquanto categoria, necessita articular estratégias de ações que rompam com o modelo de atenção em saúde revelado nesse estudo. Deve haver espaços de autonomia para o enfermeiro, mesmo diante da incongruência entre o que revela a política do programa e a prática exercida por esse profissional.

Destarte, os fatos expostos pela pesquisa demonstraram que há muito que fazer diante da implementação dos direitos sexuais e reprodutivos, enquanto direitos adquiridos e legitimados por lei, no que se refere à atuação do gestor, organização do serviço e mudanças de posturas profissionais, na superação das iniquidades e deficiências, visando à incorporação da integralidade.

Os direitos sexuais e reprodutivos, como parte integrante dos direitos humanos, necessitam atender as necessidades apresentadas pela população, para que a enfermagem se constitua enquanto categoria de produção de ações assistenciais pautadas em uma prática inclusiva, integral e eficaz.

\section{REFERÊNCIAS}

1. Costa A, Rosado L, Florêncio A, Xavier E. História do planejamento familiar e sua relação com os métodos contraceptivos. Rev Baiana Saúde Pública. 2013;37(1):74-86.

2. Lima PVC, Rocha RDL, Nery IS, Silva JCP. Uso de métodos contraceptivos por usuárias de uma unidade básica de saúde. Rev Enferm UFPI. 2015 jan-mar;4(1):11-8.

3. Silva RM, Araújo KNC, Bastos LAC, Moura ERF. Planejamento familiar: significado para mulheres em idade reprodutiva. Ciênc Saúde Coletiva. 2011;16(5):2415-24.

4. Dombrowski JG, Pontes JA, Assis WALM. Atuação do enfermeiro na prescrição de contraceptivos hormonais na rede de atenção primária em saúde. Rev Bras Enferm. 2013;66(6):827-32.

5. Silva KCS, Bonan C, Nakano AR. Estratégia saúde da família e assistência ao planejamento reprodutivo: desafios de integração, coordenação e continuidade dos cuidados. Rev APS. 2014;17(4):497-506.

6. Luiz MS, Nakano, AR, Bonan C. Planejamento reprodutivo na clínica da família de um Teias: condições facilitadoras e limites à assistência. Saúde Debate. 2015;39(106):671-82.

7. Santos JC, Freitas PM. Planejamento familiar na perspectiva do desenvolvimento. Ciênc Saúde Coletiva. 2011;16(3):1813-20.

8. Morais ACB, Ferreira AG, Almeida KL, Quirino GS. Participação masculina no planejamento familiar e seus fatores intervenientes. Rev Enferm UFSM. 2014;4(3):498-508.

9. Brasil. Ministério da Saúde. Secretaria de Atenção à Saúde. Departamento de Atenção Básica. Saúde sexual e saúde reprodutiva. 1. ed., 1. reimpr. - Brasília: Ministério da Saúde; 2013. 300 p. (Cadernos de Atenção Básica; n. 26).

10. Minayo MCS. O desafio do conhecimento. São Paulo: Hucitec; 2010.

11. Gil AC. Métodos e técnicas de pesquisa social. 6ª ed. São Paulo: Atlas; 2008. 


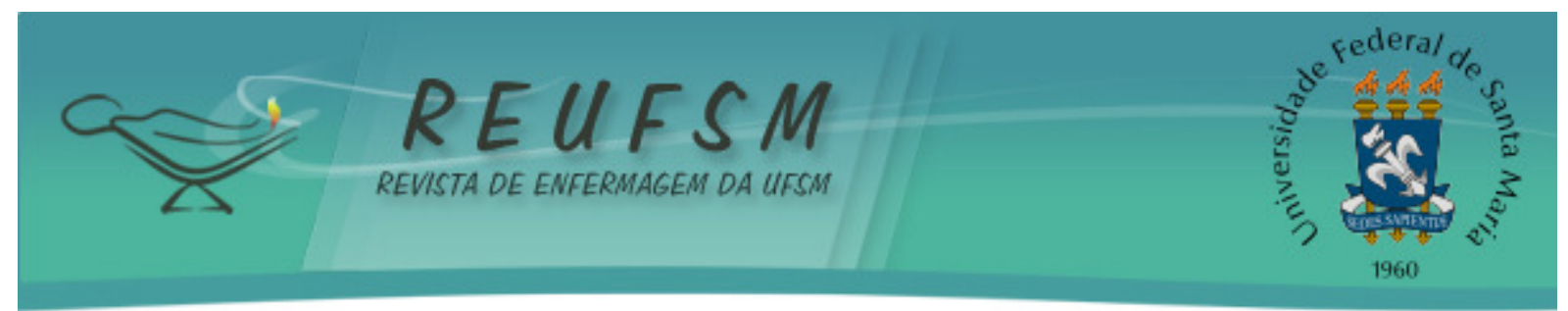

12. Fontanella BJB, Ricas J, Turato ER. Amostragem por saturação em pesquisas qualitativas em saúde: contribuições teóricas. Cad Saúde Pública. 2008;24(1):17-27.

13. Orlandi, EP. Análise de discurso: princípios \& procedimentos. $8^{\mathrm{a}}$ ed. Campinas: Pontes; 2009.

14. Silva FS, Carvalho MLO. Enfermeiros de saúde da família e ações em planejamento familiar. UNOPAR Cient, Ciênc Biol Saúde. 2007;9(1):29-36.

15. Brasil. Lei $\mathrm{n}^{\circ}$. 9.263, de 12 de janeiro de 1996. Regula o parágrafo $7^{\circ}$ do artigo $226 \mathrm{da}$ Constituição Federal, que trata do planejamento familiar, estabelece penalidades, e das outras providências. Diário Oficial da União, Brasília, DF; 1996 jan 15.

16. Moura ERF, Vieira RPR, Dias AA, Evangelista DR, Américo CF. Atenção básica e infertilidade: conhecimento e prática de enfermeiros da estratégia saúde da família. Rev Enferm UERJ. 2013;21(2):234-40.

17. Lemos A. Direitos sexuais e reprodutivos: percepção dos profissionais da atenção primária em saúde. Saúde Debate. 2014;38(101):244-53.

18. Gomes VLO, Fonseca AD, Jundi MG, Severo TP. Percepções de casais heterossexuais acerca do uso da camisinha feminina. Esc Anna Nery Rev Enferm. 2011;15(1):22-30.

19. Spinelli MBAS, Souza Al, Vanderlei LCM, Vidal SA. Características da oferta de contracepção de emergência na rede básica de saúde do Recife, Nordeste do Brasil. Saúde Soc. 2014;23(1):227-37.

20. Casarin ST, Siqueira HCH. Planejamento familiar e a saúde do homem na visão das enfermeiras. Esc Anna Nery Rev Enferm. 2014;18(4):662-8.

21. Santos AAG, Silva RM, Machado MFAS, Vieira LJES, Catrib AMF, Jorge HMF. Sentidos atribuídos por profissionais à promoção da saúde do adolescente. Ciênc Saúde Colet. 2012; 17(5):1275-84.

22. Vonk ACRP, Bonan C, Silva KS. Sexualidade, reprodução e saúde: experiências de adolescentes que vivem em município do interior de pequeno porte. Ciênc Saúde Colet. 2013;18(6):1795-807.

23. Moura LNB, Gomes KRO. Planejamento familiar: uso dos serviços de saúde por jovens com experiência de gravidez. Ciênc Saúde Colet. 2014;19(3):853-63.

24. Cabral RWL, Medeiros AL, Santos SR, Faustino CG, Campos JCS. Olhar dos acadêmicos de enfermagem acerca da prescrição de medicamentos na Estratégia Saúde da Família. Rev Enferm UFPE Online. 2014;8(11):3890-6.

25. Alves GG, Aerts D. As práticas educativas em saúde e a Estratégia Saúde da Família. Ciênc Saúde Colet. 2011;16(1):319-25.

Data de recebimento: $18 / 11 / 2015$

Data de aceite: 03/05/2016

Contato do autor responsável: Mônica Cecília Pimentel de Melo

Endereço postal: Av. José de Sá Maniçoba S/N, bairro Centro, Petrolina - PE,

Brasil. CEP 56.304-917

E-mail: monquinamelo@gmail.com 